\title{
"Virtual agency" planned for green research
}

Washington. The environmental subcommittee of the Clinton administration's new National Science and Technology Council (NSTC) could act as a "virtual agency" coordinating all the federal government's green research plans, a White House-sponsored forum was told last week.

The public forum of administration officials, scientists, environmentalists and industry representatives was the first in a series planned by the Committee on Environment and Natural Resources (CENR), one of nine committees set up by the NSTC to oversee federal research.

Robert Watson, environmental director for the White House Office of Science and Technology Policy and co-chair of the CENR, says the committee will act as a kind of "virtual agency" to orchestrate federal environmental research.

Peter Raven of the Missouri Botanical Garden in St Louis called the forum "a big success," partly because of the high level of commitment shown by the Clinton administration. Vice President Al Gore, Interior Secretary Bruce Babbitt, Environmental Protection Agency administrator Carol Browner and White House science advisor John Gibbons all spoke at the meeting. Raven says that the NSTC already has established

\section{Pacific sound experiment faces heat}

San Francisco. A global study to test the feasibility of measuring climatic changes in ocean temperature using sound has become mired in what one supporter describes as "trial by talk show".

The National Marine Fisheries Service (NMFS), flooded by a deluge of protests from environmentalists and facing likely pressure from some politicians, has delayed implementation of the $\$ 2.9$ million Acoustic Thermometry of Ocean Climate (ATOC) project, pending a series of hearings around Monterey Bay beginning April 18.

The experiment, originating at the Scripps Institution of Oceanography, would involve two underwater transducers almost a kilometre underwater off the coasts of Point Sur, California, and Kauai, Hawaii. Once every four hours, the transducers would emit a 20minute $60-90 \mathrm{~Hz}$ coded hum at up to 195 decibels. Eighteen antennae as far away as New Zealand would listen in.

Since sound travels faster in warmer water, the antennas could detect changes in temperature, providing potentially useful information to test theories of global warming.

The dispute erupted last month on MARMAM, the Internet base for marine mammologists, some of whom feared that the sound would harm or harass whales and dolphins. Two experts on sperm whales Hal Whitehead of Dalhousie University, Nova Scotia, and his wife Lindy Weilgart even claimed the noise could potentially wipe out that species. A subsequent story in the Los Angeles Times triggered considerable public alarm.

Sperm whales are the only species capable of hearing frequencies below $100 \mathrm{~Hz}$ and diving deep enough to be physically injured, according to Christopher Clark, a bioacoustician at Cornell University. But research by Darlene Ketten at Harvard suggests they would virtually have to stick their head into the speakers to be even

\section{temporarily deafened.}

Surprised and infuriated by the charges, Scripps officials denied any animals would be killed and said they would halt the experiment at the first sign any mammal was in danger.

Congressman Sam Farr (Democrat, California) says that while the experiment appears to be in the best interest of science, NMFS must address public fears. However scientists involved with ATOC fear the hearings could kill a valuable global warming experiment for no good scientific reason.

Joel Shurkin

stronger ties between scientists and policymakers than did its predecessor, the Federal Coordinating Council for Science, Engineering and Technology (FCCSET).

"This is a more powerful organization than FCCSET," he said, because "the representation is much more comprehensive than it ever was under FCCSET, and it's even more valued by the administration."

But Richard Benedick of the Committee for the National Institute for the Environment, which is pushing for a fully-fledged new agency to fund environmental research, warns that the CENR will face strong resistance from existing agencies - - especially if it tries to shift resources from government laboratories to outside scientists.

Watson acknowledges that this is a difficult problem, which he hopes to improve "at the margins" over several years. He believes that a heavy-handed attempt to shift projects from one agency to another would only result in turf battles that would leave "blood all over the floor", and would be a "nonstarter" in Congress.

But, he says, there is a real willingness in the White House and in the environmental agencies to make the CENR work. "If I heard a concern [at the meeting], it was that, while we're promoting multidisciplinary research, we may not have the mechanisms to deal with it," he said. "I heard that message loud and clear. We've now got to work for it."

Tony Reichhardt

\section{French scientists get idiots' guide to PR}

Paris. Efforts to achieve a better understanding between scientists and the media have taken a sizeable step backwards with the circulation by the French Centre National de la Recherche Scientifique (CNRS) - Europe's largest fundamental research organization - of an internal guide on how its researchers should handle journalists.

The four-page "CNRS Communications Charter" simply aims to provide researchers with the basics of communication skills, says Nicolas de Schonen, who became head of CNRS's newly-created department of corporate communications last year, after having held a similar post at EuroDisney.

The charter reminds CNRS researchers that as civil servants they are in principle forbidden from publicly criticizing CNRS or government policy. Additionally, it recommends that researchers refer all questions of policy to CNRS management or other better-informed CNRS staff. Researchers themselves, it argues, usually lack a "global view" of a given situation.

De Schonen says his message is that "it's like within a company, you can't say anything you like". The move raises the question, however, of whether the benefits of avoiding the occasional error or embarrassment outweigh the risks of encouraging the growing trend in many organizations to massage and distort information.

The charter also seems to perpetuate an "us and them" approach to media relations. Researchers are warned, for example, that journalists "need a rapid and definitive response" and may "excessively simplify" their research. Moreover, it advises that researchers "obsess" themselves with "the two or three ideas" they have prepared, and not "preoccupy" themselves "too much" with the questions they are asked. Scientists should "be positive" and "announce good news", it adds.

De Schonen defends this advice as a "provocative" means to make researchers realize that communication is "a two-way process". Corporate communications, adds the charter, can inform scientists of a given medium's "tendency", "interests", and "attitude to CNRS and the topic of research". Declan Butler 